\title{
Ecology of the African Rice Gall Midge, Orseolia oryzivora (Diptera: Cecidomyiidae) in Western Burkina Faso, West Africa
}

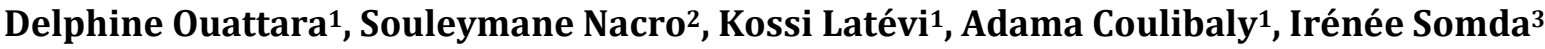 \\ ${ }^{1}$ Institut de l'Environnement et de Recherches Agricoles (INERA), Station de Recherche de Farako-Bâ, Bobo Dioulasso \\ Burkina Faso \\ ${ }^{2}$ Institut de l'Environnement et de Recherches Agricoles (INERA), Centre Régional de Formation et de Recherches \\ Environnementales et Agricoles de Kamboinsé, Ouagadougou, Burkina Faso \\ ${ }^{3}$ Université Nazi Boni, Bobo Dioulasso, Burkina Faso \\ Email: *snacro2006@yahoo.fr
}

How to cite this paper: Ouattara, D., Nacro, S., Latévi, K., Coulibaly, A. and Somda, I. (2020) Ecology of the African Rice Gall Midge, Orseolia oryzivora (Diptera: Cecidomyiidae) in Western Burkina Faso, West Africa. Advances in Entomology, 8, 1-14.

https://doi.org/10.4236/ae.2020.81001

Received: October 5, 2019

Accepted: October 29, 2019

Published: November 1, 2019

Copyright (c) 2020 by author(s) and Scientific Research Publishing Inc. This work is licensed under the Creative Commons Attribution International License (CC BY 4.0).

http://creativecommons.org/licenses/by/4.0/

\begin{abstract}
The African rice midge, Orseolia oryzivora H. \& G., is an important insect pest in Burkina Faso. Our study was conducted from 2017 to 2019 in three irrigated rice schemes including Banzon, Karfiguéla and Vallée du Kou in Western Burkina Faso. The objective of this study was to investigate the ecology of the insect pest. In each rice scheme, four plots of $500 \mathrm{~m}^{2}$ each, spread $50 \mathrm{~m}$ apart were randomly selected in farmers' fields and used for the study. In each plot, a light trap was implemented along one of the diagonals of the plot. Each light trap consisted of a yellow plastic round bowl containing soapy water almost at half the bowl and a torch. The bowl had a capacity of $4.5 \mathrm{l}$, a diameter of $28 \mathrm{~cm}$ and a height of $10.5 \mathrm{~cm}$. The torch had 3 batteries of $1.5 \mathrm{~V}$ each, $30 \mathrm{~cm}$ long and $1 \mathrm{~cm}$ diameter. The torches were lit every night at $6 \mathrm{pm}$ and off at $6 \mathrm{am}$. Four hundred tillers were collected per month from the cultivated rice and from each of the alternative hosts of the rice midge in order to evaluate the monthly gall count, pre-imaginal populations and parasitism associated with $O$. oryzivora and its cousin, $O$. bonzii that is hosted by Paspalum scrobiculatum. The number of $O$. oryzivora's adults caught in the light traps was higher during the wet season than the dry season. The level of larval parasitism ranged from $6.16 \%$ (Banzon) to $14.29 \%$ (Vallée du Kou). The highest level of pupal parasitism (13.73\%) was recorded in Vallée du Kou. The damage of $O$. oryzivora was observed on the wild rice species, $O$. longistaminata in all three sites. The highest levels of parasitism associated with $O$. bonzii were recorded in Karfiguéla $(20.08 \%$ and $25.21 \%$ for larval parasitism and pupal parasitism, respectively). These findings are useful in the
\end{abstract}


development of a sustainable control strategy of $O$. oryzivora.

\section{Keywords}

Rice, Oryza sativa, Oryza longistaminata, Orseolia oryzivora, Alternative Host Plants, Paspalum scrobiculatum, Orseolia bonzii, Burkina Faso

\section{Introduction}

In Burkina Faso, agriculture is dominated by cereals, which form the basis of the population's diet [1]. Rice has become a strategic crop because of its weight in the country's trade balance [2]. To meet the demand for rice, efforts have been made by the Burkinabè government to promote rice production through the intensification and the implementation of irrigation facilities [3]. These initiatives include agricultural research activities such as the introduction of improved varieties, and the improvement of farming techniques and practices. However, the gap between demand and domestic supply is closely related to the various constraints facing rice production. These constraints induce a production loss of $2 \%$ to $38 \%$ depending on the growing season [4]. Among the biotic constraints, insect pests occupy an important place. The African rice midge, Orseolia oryzivora is an important insect pest reported in several African countries [5]. In Burkina Faso, the midge is best known in the western and southwestern regions thanks to the good rainfall conditions and the presence of host plants all year round [6]. It can cause up to $70 \%$ damage to rice tillers in these regions of the country [5], as well as yield losses up to $80 \%$ in West Africa [7]. The young larva of the midge feeds inside the young tiller causing the formation of a long tubular gall. Each gall is a loss tiller. The study of the ecology of the insect pest is a pre-requisite for the development of sustainable control methods. This is what this study was meant for.

\section{Material and Methods}

\subsection{Material}

\subsubsection{Study Site}

The study was conducted on 3 rice schemes including Karfiguéla, Banzon and the Vallée du Kou, western Burkina Faso. It was carried out in the South Sudanese climatic zone [8]. This is the most humid region of the country with annual rainfall between 900 and $1200 \mathrm{~mm}$. The study sites are irrigated schemes, with 2 cropping seasons per year, the first one (dry season) starting in January and ending in May and the second cropping season (wet season) running from July to November.

The Banzon rice scheme is located in the Hauts-Bassins region, $65 \mathrm{~km}$ from Bobo-Dioulasso between parallels $4^{\circ} 30^{\prime}$ and $5^{\circ} 30^{\prime}$ West longitude and $10^{\circ} 10^{\prime}$ and $12^{\circ} 05^{\prime}$ latitude North. This scheme includes a total area of 454 ha that is farmed 
by 632 farmers. The relative humidity varies between $58 \%$ and $66.46 \%$. Temperatures range from $28.5^{\circ} \mathrm{C}$ to $30.35^{\circ} \mathrm{C}$ while the average annual rainfall is 966.6 $\mathrm{mm}$.

- Karfiguéla is located at $10^{\circ} 70^{\prime}$ North latitude and $4^{\circ} 8^{\prime}$ West longitude, $10 \mathrm{~km}$ North-West of Banfora in the Cascades region, $95 \mathrm{~km}$ South of Bobo-Dioulasso, the second largest city of Burkina Faso. About 400 farmers share this irrigated rice scheme of 332 ha. The area is under cultivation since 1977. Irrigation is done from the Cascades of the Comoé River. The wet season is characterized by a relatively high monthly rainfall between May and September ranging from $957 \mathrm{~mm}$ to $1226.0 \mathrm{~mm}$. The humidity levels are between $14 \%$ and $88 \%$. Maximum temperatures range from $28.5^{\circ} \mathrm{C}$ to $30.35^{\circ} \mathrm{C}$ while minimum temperatures range from $20.1^{\circ} \mathrm{C}$ to $24.8^{\circ} \mathrm{C}$.

- The rice-growing area of the Kou Valley is located $25 \mathrm{~km}$ North-West of Bobo-Dioulasso in the Hauts-Bassins region between the parallels $10^{\circ} 20^{\prime}$ North and $4^{\circ} 20^{\prime}$ West longitude. With a total area of 1260 ha, the Vallée du Kou with total water control is part of a vast plain of 9700 ha of which 2300 ha are under cultivation. This scheme is currently operated by 1300 farmers. The relative humidity varies between $56 \%$ and $75.3 \%$. Temperatures range from $26^{\circ} \mathrm{C}$ to $28.5^{\circ} \mathrm{C}$. The annual average rainfall is $1154 \mathrm{~mm}$.

\subsubsection{Climatic Characteristics of the Study Sites}

The meteorological data recorded included rainfall, relative humidity and temperature.

Figure 1 shows rainfall trends in the three rice sites from May 2017 to April 2019. In fact, the total precipitation recorded in the 2017 wet season was 1124.4 $\mathrm{mm}$ in Banzon as compared to $1053.7 \mathrm{~mm}$ in the Kou Valley and $783.7 \mathrm{~mm}$ in Karfiguéla. On the other hand, in the 2018 dry season, they were $87.7 \mathrm{~mm}$ in Karfiguéla against $57 \mathrm{~mm}$ in Banzon and $19.9 \mathrm{~mm}$ in Vallée du Kou. During the 2018 wet season, however, Banzon recorded $966.6 \mathrm{~mm}$ against $1178.5 \mathrm{~mm}$ in Karfiguéla and $1154 \mathrm{~mm}$ in the Vallée du Kou. In the 2019 dry season, the rainfalls recorded were $76 \mathrm{~mm}$ in the Banzon site, $57.6 \mathrm{~mm}$ in the Karfiguela site and $41.7 \mathrm{~mm}$ in the Vallée du Kou site. Rains were recorded during the dry season, particularly in April in the three sites. Most of the rains were recorded in August in all study sites.

Regarding the relative humidity, the maximum was recorded at the Banzon site during the 2019 wet season in July, with $90 \%$. The relative air humidity ranged from $67.3 \%$ to $89 \%$ during the 2017 wet cropping season as compared to $40.9 \%$ to $61 \%$ in the 2018 dry cropping season. During the 2018 wet cropping season the highest relative humidity (90\%) was recorded in Banzon in July and the lowest (65.3\%) in Vallée du Kou in May. The lowest relative humidity was recorded in February and the highest in July and August. In Vallée du Kou, the relative humidity ranged from $47 \%$ to $84.5 \%$ throughout the three years of the study. On this site also, the lowest relative humidity was recorded in February and the highest in August and September (Figure 2). However, the relative 


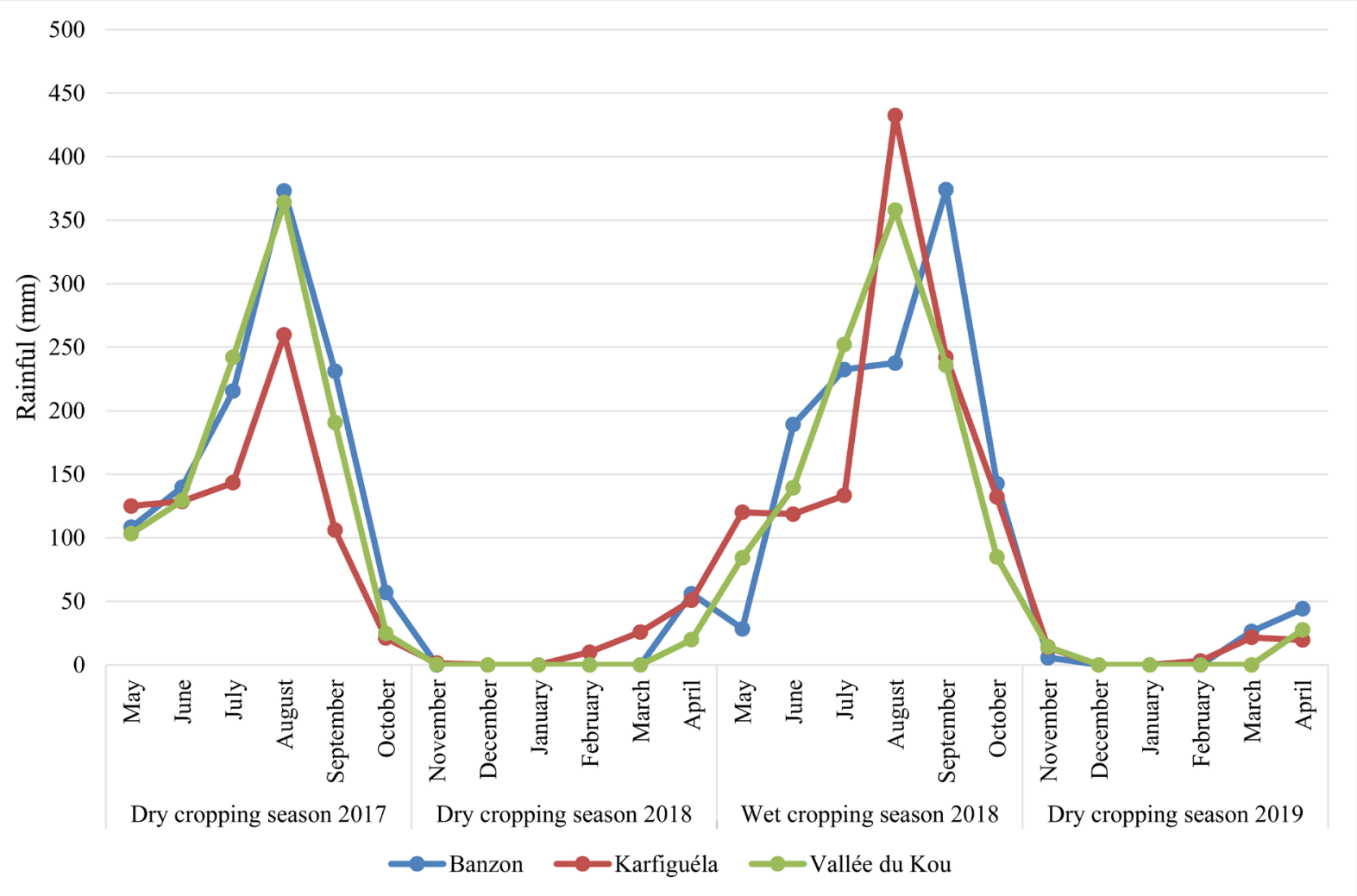

Figure 1. Rainfall (mm) recorded in study sites from 2017 to 2019.

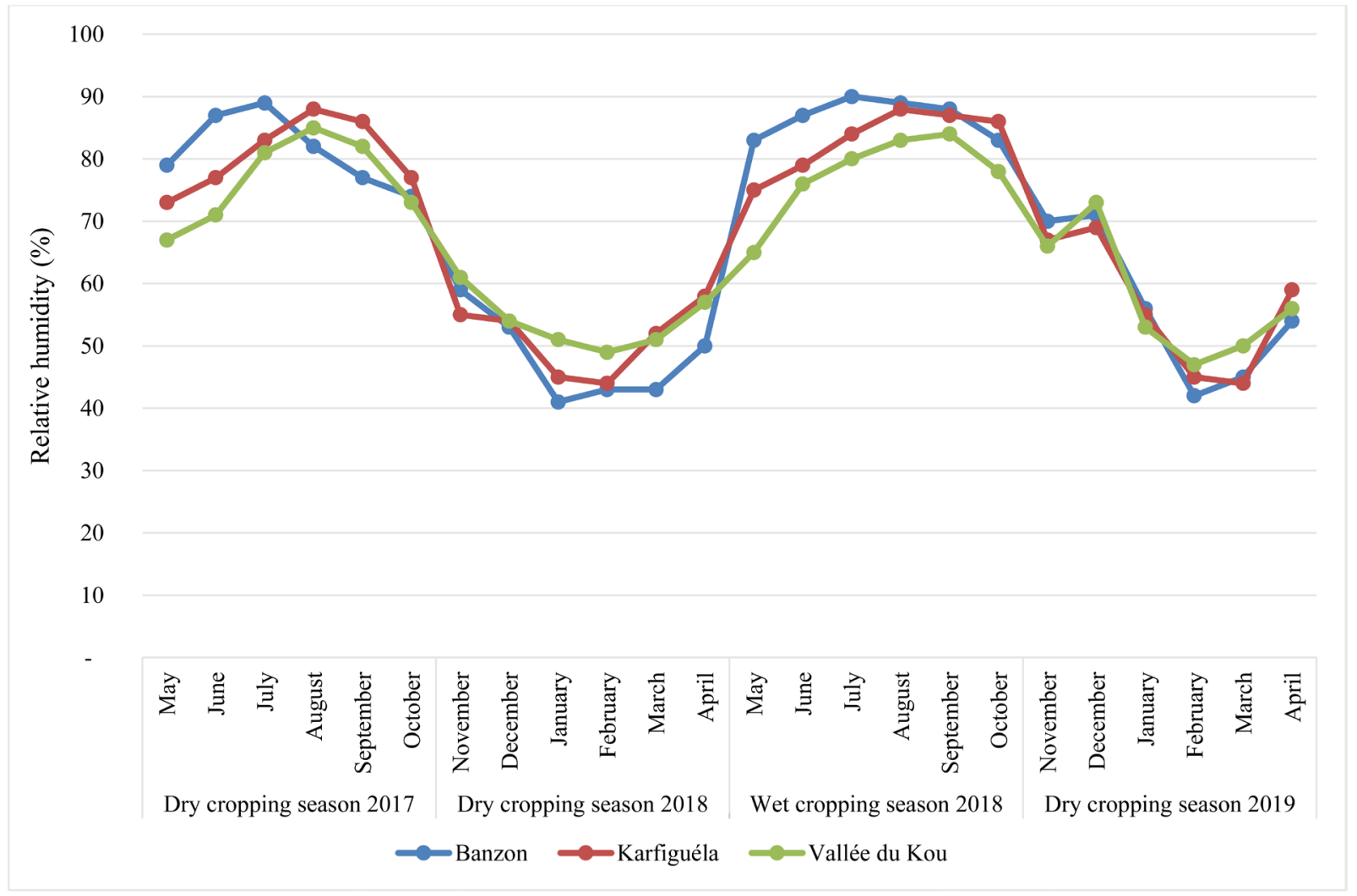

Figure 2. Average relative humidity on study sites recorded from 2017 to 2019. 
humidity was relatively higher in Karfiguéla during the two wet seasons of 2017 and 2018 (72\% to $88 \%)$.

Figure 3 illustrates the evolution of the average temperatures during the wet seasons $(2017,2018)$ and the dry seasons $(2018,2019)$. Average temperatures ranged from $26.1^{\circ} \mathrm{C}$ to $29.5^{\circ} \mathrm{C}$ in Karfiguéla, from $25.2^{\circ} \mathrm{C}$ to $30.25^{\circ} \mathrm{C}$ in Banzon and from $26^{\circ} \mathrm{C}$ to $28.7^{\circ} \mathrm{C}$ in the Vallée du Kou during the wet cropping seasons 2017 and 2018. The temperatures recorded during the dry cropp in seasons 2018 and 2019 ranged between $26.7^{\circ} \mathrm{C}$ and $31.9^{\circ} \mathrm{C}$ in Karfiguéla versus $26.2^{\circ} \mathrm{C}$ and $31.9^{\circ} \mathrm{C}$ in Banzon and between $23^{\circ} \mathrm{C}$ and $31.2^{\circ} \mathrm{C}$ in Vallée du Kou. The months of December, January, and February were generally the coldest of the year as opposed to the hottest months of March and April.

\subsubsection{Plant Material}

- Paspalum scrobiculatum Linnaeus: it is a perennial wild grass with broad stems bushy from 15 to $100 \mathrm{~cm}$ high. Its inflorescence is a terminal panicle carrying spikelets. It is found in rice-growing areas on separation bunds or fallow fields [9].

- Rice ratoons are encountered on rice fields after rice harvest of the wet cropping season and at the end of the dry season in April.

- Oryza longistaminata is present in rice ecosystems in various habitats (canals, irrigation, bunds and lowlands). It is a perennial plant that grows thanks to its rhizomes. The plant has a spongy stem up to two meters high. Its inflorescence

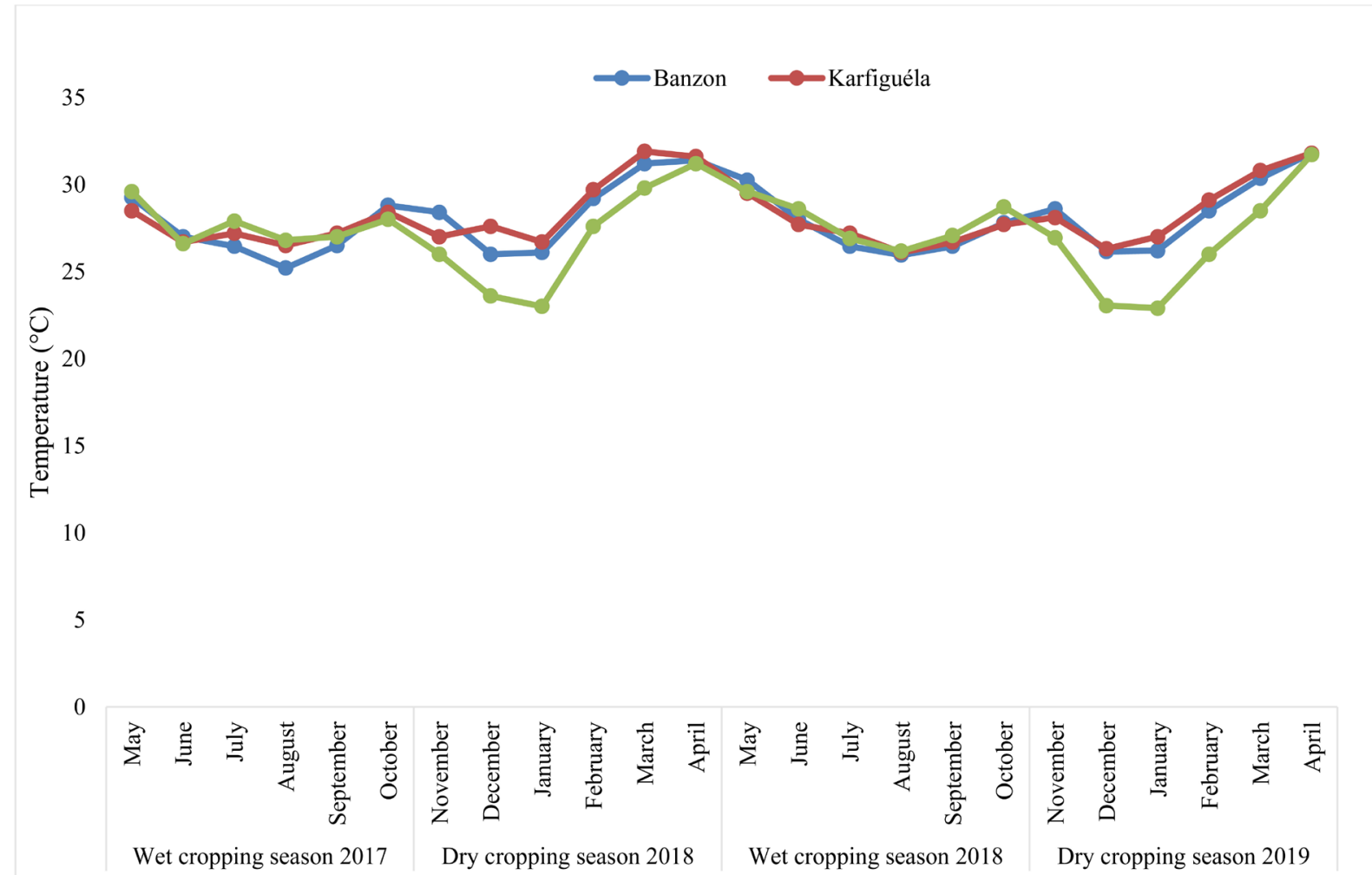

Figure 3. Average monthly temperatures recorded on study sites from 2017 to 2019. 
is an erect panicle with barbed spikelets [9].

- - Oryza sativa: it was used in all 3 rice schemes and the varieties used included FKR 58N, FKR 60N, FKR 62N and TS2.

\subsection{Methods}

The study was conducted in 3 sites including Banzon, Karfiguéla and Vallée du Kou during four consecutive rice cropping seasons from 2017 to 2019:

- two wet cropping seasons from May to October;

- two dry cropping seasons from November to April;

The temperature of the three localities was measured daily to monitor its influence on the evolution of the insect pests and their associated parasitoids. In the laboratory, temperature was maintained at $28^{\circ} \mathrm{C}$ and was measured every morning.

\subsubsection{Field Sampling Methods}

Sampling was done monthly to monitor the ecology of the two parasitoids $P$. diplosisae and $A$. procerae affecting $O$. oryzivora in farmers' fields. Four elementary plots with an area of $500 \mathrm{~m}^{2}$ each and $50 \mathrm{~m}$ apart from each other were chosen in farmers' fields. The four elementary plots represented four replications. All plots were subjected to the same cultural and irrigation practices. A light trap was implemented in each elementary plot. The sampling was carried out monthly and consisted in the observation of the midge damage on cultivated rice in farmers' fields, on wild rice in the surroundings and on rice ratoons after harvest. Sampling of rice tillers was also randomly done diagonally across the four selected plots. One hundred tillers were collected per week i.e. 400 tillers per month. In each field, the observations consisted of counting in a quadrat of $1 \mathrm{~m}^{2}$ chosen at random, the total number of tillers and the number of galls. The percentage of galls was calculated from the ratio of the number of galls to the total number of tillers. An average damage per quadrat of $1 \mathrm{~m}^{2}$ was reported monthly. After each harvest, 100 tillers from rice ratoons were collected and dissected each month. The following variables were recorded from the dissected material: the number of galls, the number of larvae and the number of pupae. The percentage of the pre-imaginal population of the midge was calculated from the ratio of the number of larvae and pupae to the total number of tillers (400) and the percentage of galls from the ratio of the number of galls to the number of tillers (400). On wild rice, observations consisted of monthly sampling at each of the plant sites in the irrigation canals, bunds and fallow fields from which 100 tillers were collected and dissected per month. The observations consisted in counting the number of midge larvae and pupae and the number of galls. The percentage of the pre-imaginal population was calculated from the ratio of the number of larvae and pupae to the total number of tillers (400) and the percentage of galls from the ratio of the number of galls to the total number of tillers (400) according to the following formula:

- $\%$ of pre-imaginal populations of $O$. oryzivora: $(\mathrm{L}+\mathrm{P}) / \mathrm{T} \times 100(\mathrm{~L}=$ number of larvae; $\mathrm{P}=$ number of pupae; $\mathrm{T}=$ number of tillers); 
- $\quad \%$ galls: $\mathrm{G} / \mathrm{T} \times 100$ ( $\mathrm{G}=$ number of galls; $\mathrm{T}=$ total number of tillers).

The $\%$ of larval parasitism was calculated from the ratio of the number of parasitized larvae to the number of non-parasitized larvae plus the number of parasitized larvae: $\mathrm{PL} /(\mathrm{NPL}+\mathrm{PL}) \times 100$ where $\mathrm{PL}=$ parasitized larvae; $\mathrm{NPL}=$ non-parasitized larvae.

The \% of pupal parasitism was calculated from the ration of the number of parasitized pupae to the number of non-parasitized pupae plus the number of parasitized pupae: $\mathrm{PP} /(\mathrm{NPP}+\mathrm{PP}) \times 100$ where $\mathrm{PP}=$ parasitized pupae; $\mathrm{NPP}=$ non-parasitized pupae.

The cumulative parasitism was computed by dividing the number of parasitized larvae and parasitized pupae by the number of non-parasitized larvae plus the number of non-parasitized pupae, plus the number of parasitized larvae, plus the number of parasitized pupae): $((\mathrm{PL}+\mathrm{PP}) /(\mathrm{PL}+\mathrm{PP}+\mathrm{NPL}+\mathrm{NPP})) \times 100$ where $\mathrm{PL}=$ parasitized larvae; $\mathrm{PP}=$ parasitized pupae; $\mathrm{NPL}=$ non-parasitized larvae; NPP = non-parasitized pupae.

Light trapping consisted of implementing one trap at the center of one of the diagonals of each selected plot. Each light trap consisted of a round plastic bowl of yellow color (capacity: 4.5 l, diameter: $28 \mathrm{~cm}$ and height: $10.5 \mathrm{~cm}$ ) containing soapy water almost at half the bowl. The bowl was placed on a wooden support at $1 \mathrm{~m}$ from the ground, a torch of $31.5 \mathrm{~V}$ batteries was suspended on the bowl. The torches were lit every evening (at dusk). Each morning, the content of each cuvette was removed, sieved and stored in empty bottles $(250 \mathrm{ml})$ containing alcohol diluted to $70^{\circ}$. The collection of specimens was kept in 4 bottles every week, i.e. 16 bottles per month. At the end of the trapping activity, all the bottles containing the captured insects were brought back to the entomology laboratory for the counting and identification. The catches were grouped by season (May to October for the wet cropping season and from November to April for the dry cropping season) in order to make a comparison between the 3 sites for each of the 2 seasons.

\subsubsection{Data Processing and Analysis}

Data were entered into the Microsoft Excel 2010 spreadsheet and statistical analysis was performed with XLSTAT software version 2010.7.02. Data that did not conform normal distribution were first transformed (to normalize) using one of the following mathematical formulas $\log 10(\mathrm{x}+1)$ or $\operatorname{Arcsin}(\mathrm{x}+1)$ for continuous, discontinuous or percentage variables, before performing the analysis of variance. The transformed data were subjected to a nonparametric test (the Kruskal Wallis test) with SPSS software version 23. Means were separated using the Fisher test at 5\% threshold, when significant differences were revealed by the analysis of variance.

\section{Results and Discussion}

\subsection{Results}

\subsubsection{Evolution of the Adult Populations of $\boldsymbol{O}$. oryzivora}

The number of $O$. oryzivora's adults caught in the light traps varied according to 
seasons and sites. Overall, the number of the adults caught was higher during the wet season than the dry season (Table 1). Over all seasons, the largest catches were recorded in Karfiguéla (Table 1). The analysis of variance revealed a significant difference between sites during the two wet seasons. During the 2017 wet season, an average of 117.56 midges was recorded in Karfiguéla, 124 in Vallée du Kou and 44.19 in Banzon. Catches were low at all three sites during the two dry seasons, 2018 and 2019; this number was higher during the wet season 2018: 128.92 midges were collected in Vallée du Kou, 122.75 in Karfiguéla and 49.17 in Banzon (Table 1).

During the 2017 wet season, the first adult of $O$. oryzivora was recorded in May (Figure 4). The peak of the population was observed in September 2017

Table 1. Results of the analysis of variance on the average numbers of $O$. oryzivora adults on study sites from de 2017 à 2019.

\begin{tabular}{ccccc}
\hline \multicolumn{5}{c}{ Seasons } \\
\hline Sites & Wet season 2017 & Dry season 2018 & Wet season 2018 & Dry season 2019 \\
\hline Banzon & $44.19 \pm 27.89^{\mathrm{b} *}$ & $14.38 \pm 7.72$ & $49.17 \pm 27.87^{\mathrm{b}}$ & $19.22 \pm 7.73$ \\
Karfiguéla & $117.56 \pm 39.79^{\mathrm{a}}$ & $39.38 \pm 36.23$ & $122.75 \pm 39.77^{\mathrm{a}}$ & $44.38 \pm 36.29$ \\
Vallée du Kou & $124 \pm 43.56^{\mathrm{a}}$ & $37.5 \pm 35.58$ & $128.92 \pm 43.52^{\mathrm{a}}$ & $42.46 \pm 35.54$ \\
Probability & 0.004 & 0.296 & 0.004 & 0.292 \\
Significance & $\mathrm{S}$ & $\mathrm{NS}$ & $\mathrm{S}$ & $\mathrm{NS}$ \\
\hline
\end{tabular}

*Numbers followed by the same letter are not significantly different at $5 \%$ probability.

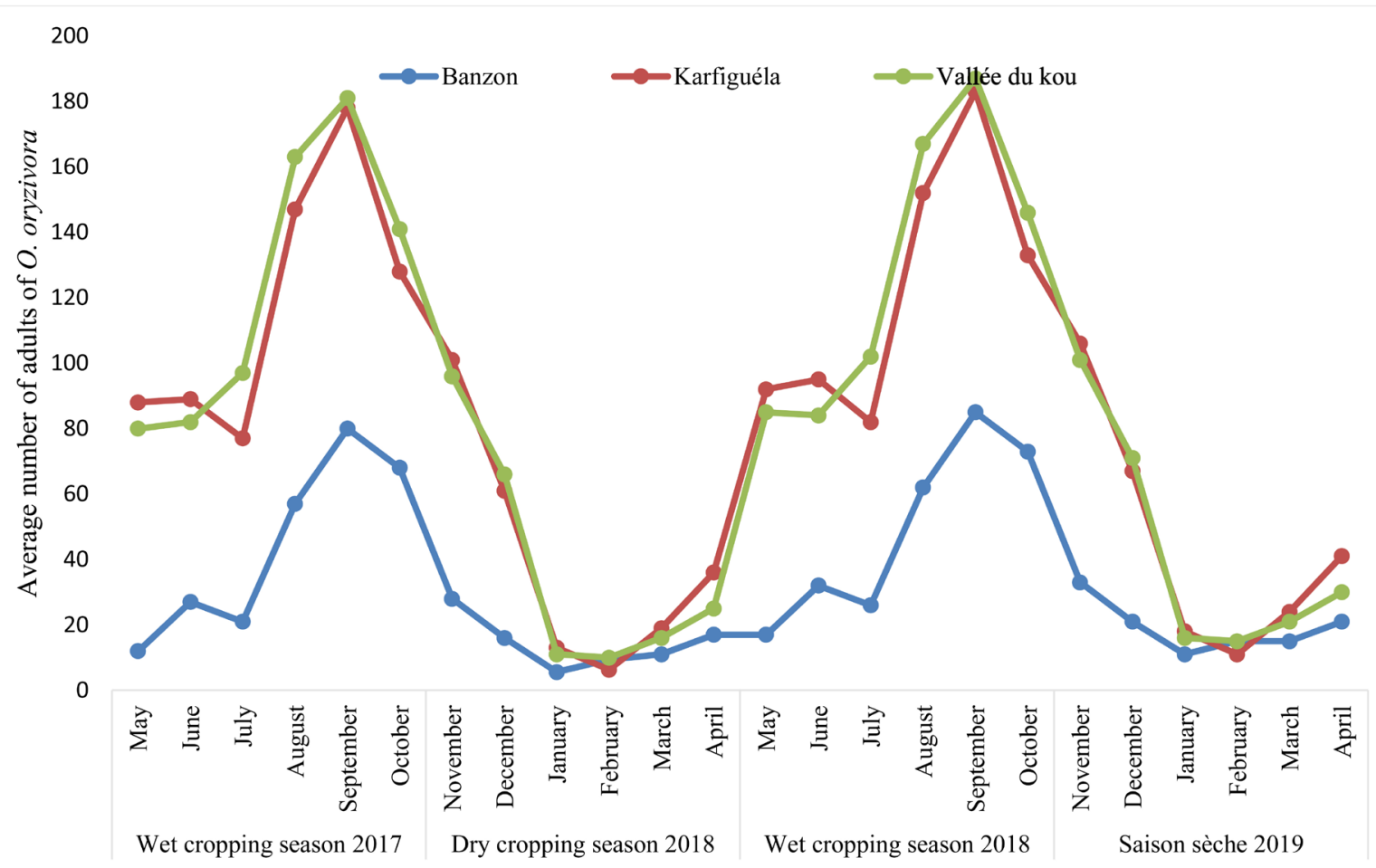

Figure 4. Evolution of the adult populations of O. oryzivora from 2017 to 2019 in western Burkina Faso. 
with 181.25 midges in Karfiguéla, 177.5 in Vallée du Kou and 80 in Banzon. This population decreased from October 2017 in all three sites (Figure 4) until the dry season (November, December). The populations remained low from January to April of the 2018-2019 dry season on the different sites. However, as of May 2018, there was a slight increase in the midge population until July; then an important increase was observed in August with a peak reached in September of the wet season 2018: 186.5 midges recorded in Vallée du Kou, 182.5 midges in Karfiguela and 85 midges in Banzon (Figure 4).

\subsubsection{Evolution of the Damage of $O$. oryzivora on Cultivated Rice}

The midge's damage was observed in all sites as early as May 2017. The damage varied with the seasons (Table 2). ANOVA revealed a non-significant difference between the sites during the consecutive wet seasons 2017 and 2018 and the 2018 dry season. However, a significant difference $(\mathrm{p}=0.039)$ was observed between the sites during the 2019 dry season. During the 2017 wet season the following figures were recorded: $6.42 \%$ of galls in Vallée du Kou; 6.25\% galls in Karfiguéla and finally $1.54 \%$ galls in Banzon. The damage of the midge was respectively 8.58\%, $6.67 \%$ and $0.83 \%$ in Karfiguéla, Vallée du Kou and Banzon during the wet 2018 season. The damage recorded during the 2019 dry season was higher than that recorded during the 2018 dry season: Vallée du Kou (5.54\% vs. $4.25 \%$ ); Karfiguela ( $4.92 \%$ vs. $3.33 \%)$ and Banzon (0.08\% vs. $0.05 \%)$ (Table 2$)$.

\subsubsection{Evolution of the Damage of 0 . oryzivora and Its Associated Parasitoids on Rice Ratoons}

Although very low, or even negligible, the damage due to $O$. oryzivora was observed on rice ratoons and in all the study sites from 2017 to 2019. However, for this variable, no significant difference was found between the different sites whatever the year and the cropping season. These observations are also valid for the larvae and the pupae of $O$. oryzivora (Table 3). Levels of larval parasitism ranging from $6.16 \%$ (Banzon) to $14.29 \%$ (Vallée du Kou) were recorded at the 3 study sites, although no significant difference between the sites was revealed. The highest level of pupal parasitism (13.73\%) was recorded in Vallée du Kou. This level is followed by that recorded of Karfiguéla (11.29\%) and Banzon (5.08\%).

Table 2. Results of the analysis of variance on the damage of $O$. oryzivora on study sites from 2017 to 2019.

\begin{tabular}{ccccc}
\hline \multicolumn{5}{c}{ Seasons } \\
Sites & Wet season 2017 & Dry season 2018 & Wet season 2018 & Dry season 2019 \\
\hline Banzon & $1.54 \pm 0.83$ & $0.05 \pm 0.01$ & $0.83 \pm 0.04$ & $0.08 \pm 0.02^{\mathrm{b} *}$ \\
Karfiguéla & $6.25 \pm 5.76$ & $3.33 \pm 2.13$ & $8.58 \pm 6.64$ & $4.92 \pm 3.2^{\mathrm{a}}$ \\
Vallée du kou & $6.42 \pm 3.82$ & $4.25 \pm 3.01$ & $6.67 \pm 4.96$ & $5.54 \pm 3.66^{\mathrm{a}}$ \\
Probability & 0.183 & 0.063 & 0.076 & 0.039 \\
Signification & $\mathrm{NS}$ & $\mathrm{NS}$ & $\mathrm{NS}$ & $\mathrm{S}$ \\
\hline
\end{tabular}

${ }^{*}$ Numbers followed by the same letter are not significantly different at the $5 \%$ probability. 


\subsubsection{Seasonal Evolution of O. oryzivora's Damage on Oryza longistaminata}

The damage of $O$. oryzivora was observed on the wild rice species, $O$. longistaminata in all three sites. The ANOVA revealed no significant differences $(p=0.21)$ between seasons and sites with respect to the damage of the midge (Table 4). In fact, the highest seasonal damage $(0.75 \%)$ was recorded during the 2017 wet cropping season in Vallée du Kou. However, this level of damage was successively recorded in Karfiguéla during the 2018 dry cropping season (0.75\%), the wet cropping season (0.83\%) and during the 2019 dry cropping season (0.88\%) (Table 4). The lowest damage levels were recorded in Banzon, during all considered cropping seasons.

Table 3. Results of the analysis of variance of the damage of $O$. oryzivora on rice ratoons on study sites from 2017 to 2019.

\begin{tabular}{|c|c|c|c|c|c|c|}
\hline & & Galls (\%) & Larvae (\%) & $\begin{array}{l}\text { Parasitized } \\
\text { larvae (\%) }\end{array}$ & Pupae (\%) & $\begin{array}{c}\text { Parasitized } \\
\text { pupae (\%) }\end{array}$ \\
\hline \multirow[t]{3}{*}{ Sites } & Vallée du Kou & 1.31 & 0.43 & 14.29 & 0.26 & 13.73 \\
\hline & Karfiguéla & 0.82 & 0.22 & 8.12 & 2.26 & 11.29 \\
\hline & Banzon & 0.28 & 0.09 & 6.16 & 0.09 & 5.08 \\
\hline $\mathbf{x}^{2}$ & & 3.11 & 3.13 & 1.13 & 1.42 & 1.53 \\
\hline Probability & & 0.21 & 0.21 & 0.56 & 0.49 & 0.46 \\
\hline \multirow[t]{2}{*}{ Saisons } & Wet season & 0.54 & 0.16 & 5.72 & 0.16 & 5.64 \\
\hline & Dry season & 1.06 & 0.33 & 13.33 & 0.25 & 14.44 \\
\hline$x^{2}$ & & 1.39 & 0.56 & 1.83 & 2.13 & 2.34 \\
\hline Probability & & 0.23 & 0.45 & 0.17 & 0.14 & 0.12 \\
\hline \multirow[t]{3}{*}{ Years } & 2017 & 0.66 & 0.12 & 9.22 & 0.26 & 8.5 \\
\hline & 2018 & 0.72 & 0.25 & 8.05 & 0.12 & 9.94 \\
\hline & 2019 & 1.11 & 0.36 & 12.77 & 0.32 & 11.77 \\
\hline$x^{2}$ & & 0.27 & 0.12 & 0.40 & 0.47 & 0.22 \\
\hline Probability & & 0.87 & 0.94 & 0.82 & 0.79 & 0.90 \\
\hline
\end{tabular}

Table 4. Results of the analysis of variance of the damage (\%) of O. oryzivora on Oryza longistaminata on study sites from 2017 to 2019.

\begin{tabular}{ccccc}
\hline \multicolumn{5}{c}{ Seasons } \\
\hline Sites & Wet 2017 & Dry 2018 & Wet 2018 & Dry 2019 \\
\hline Banzon & $0.08 \pm 0.2$ & $0.21 \pm 0.10$ & $0.04 \pm 0.01$ & $0.17 \pm 0.03$ \\
Karfiguéla & $0.42 \pm 0.05$ & $0.75 \pm 0.12$ & $0.83 \pm 0.09$ & $0.88 \pm 0.11$ \\
Vallée du kou & $0.75 \pm 0.09$ & $0.38 \pm 0.06$ & $0.75 \pm 0.11$ & $0.38 \pm 0.06$ \\
Probability & 0.25 & 0.27 & 0.24 & 0.26 \\
Signification & NS & NS & NS & NS
\end{tabular}




\subsubsection{Evolution of the Pre-Imaginal Populations of Orseolia bonzii on Paspalum scrobiculatum}

Table 5 illustrates $O$. bonzii damage to $P$. scrobiculatum based on study sites, cropping seasons, and years. The analysis of variance revealed highly significant differences between the sites with respect to the 3 studied parameters: galls ( $\mathrm{p}=$ $0.001)$, larval $(\mathrm{p}=0.001)$ and pupal $(\mathrm{p}=0.002)$ levels. The highest average gall level (1.16\%) was recorded in Vallée du Kou. There were significantly more galls during the wet cropping season $(1.13 \%)$ than the dry cropping one $(0.36 \%)$. During the 2017 wet cropping season, the levels of larval and pupal parasitism were respectively $16.16 \%$ and $27.22 \%$. In 2018 , these figures were respectively $11.38 \%$ and $11 \%$ while $10 \%$ of larval parasitism and $3 \%$ of pupal parasitism were recorded in 2019. However, no significant difference was found between years for parasitism. The highest levels of parasitism were recorded in Karfiguéla (20.08\% and $25.21 \%$ for larval parasitism and pupal parasitism, respectively). Analysis of variance revealed a significant difference between rice schemes for this variable. No parasitism was observed in the Banzon site. Parasitism associated with $O$. bonzii was higher during the wet season than the dry season. The level of parasitized pupae was significantly higher during the wet season than the dry season.

\subsection{Discussion}

\subsubsection{Evolution of the Adult Populations of O. oryzivora}

The abundance of the adult populations of $O$. oryzivora varied according to the

Table 5. Results of the analysis of variance of the damage of $O$. bonzii and the level of parasitism associated with the midge on study sites from 2017 to 2019.

\begin{tabular}{ccccc}
\hline & & Galls $(\%)$ & Parasitized larvae (\%) & Parasitized pupae (\%) \\
\hline Sites & Vallée du Kou & $1.16^{\mathrm{a}}$ & $14.04^{\mathrm{a}}$ & $19.21^{\mathrm{a}}$ \\
& Karfiguéla & $1.07^{\mathrm{b}}$ & $20.08^{\mathrm{b}}$ & $25.22^{\mathrm{b}}$ \\
& Banzon & $0^{\mathrm{c}}$ & $0^{\mathrm{c}}$ & $0^{\mathrm{c}}$ \\
$\mathbf{x}^{2}$ & & 10.69 & 10.69 & 9.30 \\
Probability & & 0.001 & 0.001 & 0.002 \\
Seasons & Wet season & $1.13^{\mathrm{a}}$ & 15.02 & $23.69^{\mathrm{a}}$ \\
& Dry season & $0.36^{\mathrm{b}}$ & 7.72 & $5.75^{\mathrm{b}}$ \\
$\mathbf{x}^{2}$ & & 4.31 & 2.21 & 0.016 \\
Probability & & 0.04 & 0.147 & 0.122 \\
Years & 2017 & 1.15 & 16.16 & 27.22 \\
& 2018 & 0.68 & 11.40 & 11 \\
& 2019 & 0.46 & 10 & 3 \\
$\mathbf{x}^{2}$ & & 1.55 & 1.08 & 2.67 \\
Probability & & 0.46 & 0.582 & 0.262 \\
\hline
\end{tabular}

${ }^{\star}$ Numbers followed by the same letter are not significantly different at the $5 \%$ probability. 
seasons and the sites during the study period. The number of adults caught was always higher during the wet cropping seasons (2017 and 2018) than the dry cropping seasons (2018 and 2019). The peaks of adult catches were observed in September of the two consecutive years, 2017 and 2018. During this study, the month of September was characterized on average by a temperature of $28.5^{\circ} \mathrm{C}$ and a relative humidity of $90 \%$ in Karfiguéla. According to [5] and [10], relative humidity above $60 \%$ and temperature between $25^{\circ} \mathrm{C}$ and $35^{\circ} \mathrm{C}$ provide optimal conditions for midge development. Our results are close to those reported by [11] who highlighted the fact that O. oryzivora is a pest of wet season. On the other hand, during the dry season, the decrease in the midge populations is explained by the unfavorable climatic conditions.

\subsubsection{Evolution of the Damage of $O$. oryzivora on Cultivated Rice}

Like the seasonal evolution of the midge adult populations, the damage of the pest in the three sites was high during the wet cropping seasons 2017 and 2018 and almost absent during the 2018 and 2019 dry cropping seasons. Climatic factors, particularly rainfall and relative humidity, partly explain these results. Abundant rainfall, overcast skies and high relative humidity have been identified as key factors for the populations growth of the Asian rice midge, Orseolia oryzae [11]. In Burkina Faso, [5] [11] [12] and [13] made similar observations in the variation in abundance of $O$. oryzivora populations in the south-west of the country. However, the absence of damage following a decrease in the population of the insect pest during the dry season is explained by climatic conditions that are particularly unfavorable for the development of the midge (low relative humidity and no rain). The damage observed on cultivated rice during the wet seasons on all three sites was lower than or equal to $15 \%$ due to the low rainfall of the 2017 cropping season while $18 \%$ of damage was recorded during the 2018 wet cropping season due to more important rains. These observations are similar to those reported by [11] [14] and [15]. But the $60 \%$ damage reported by [6] is far higher than the maximum (18\%) recorded during our study. The results reported by [6] were published back in mid-1980 when the damage of $O$. oryzivora was particularly important in Karfiguéla rice scheme because of bad agricultural practices including the spreading of the planting dates, the use of several rice varieties with different durations, the presence of weeds in the canals etc. Since the early 2000, rice farmers of this region have benefited several trainings in integrated pest management (IPM) that have led to a significant reduction in the use of chemical insecticides and the damage of insect pests including $O$. oryzivora.

During both dry cropping seasons, 2018 and 2019, O. oryzivora damage was observed only in Vallée du Kou and Karfiguéla and the level of this damage was low. These results can be explained by climatic conditions (relative humidity between $49 \%$ and $57 \%$ with a minimum temperature of $22.96^{\circ} \mathrm{C}$ ) which are unfavorable to the development of the midge. Adverse weather conditions, particularly a minimum temperature of $26.1^{\circ} \mathrm{C}$ and above all a relative humidity of between $22.9 \%$ and 50\%, explain the results at the Banzon site. 


\subsubsection{Evolution of Pre-Imaginal Populations of $O$. oryzivora on Oryza sativa, 0 . longistaminata and Rice Ratoons}

Wild rice, $O$. longistaminata, hosted pre-imaginal populations of $O$. oryzivora at low levels. The highest gall levels were recorded in Vallée du Kou during the two wet cropping seasons, 2017 and 2018. Our results corroborate those of [11] and [13] who found similar damage levels in Karfiguéla and Vallée du Kou on the same host plant. However, during the two dry cropping seasons, 2018 and 2019, the damage of $O$. oryzivora on $O$. longistaminata was observed only in Karfiguela. The almost continuous presence of the midge on O. longistaminata all year round is an evidence that this host plant plays an important role in the survival of $O$. oryzivora populations between two rice cropping seasons. We observed $5.25 \%$ of galls on rice ratoons in Vallée du Kou. These results corroborate those of [16] who reported $6.6 \%$ of galls on ratoons in this rice scheme.

\section{Acknowledgements}

Authors thank the rice research program of INERA for providing funding for these investigations. They also thank the technicians of Banzon, Karfiguéla and Vallée du Kou and Mr. Youssouf Traoré for their contribution to data collection.

\section{Conflicts of Interest}

The authors declare no conflicts of interest regarding the publication of this paper.

\section{References}

[1] FAO (2017) Monitoring of Rice Market by FAO. Analysis of the Recent Evolution of the World Rice Market and Perspectives in the Short Term.

[2] FAOSTAT (2017) Production of the Main Crops in the World. http://www.faostat.org/

[3] WBG (2015) Thematic Report on Agriculture Chains in Sahel. Initiative for Irrigation in Sahel-Lead Analytica Consultation Services for the Wordl Bank 66 p, 2015.

[4] Ba, N.M., Dakouo, D., Nacro, S. and Karamage, F. (2008) Seasonal Abundance of Lepidopterou Stem Borers and Diopsid Flies in Irrigated Fields of Cultivated (Oryza sativa) and Wild Rice (Oryza longistaminata) in Western Burkina Faso. International Journal of Tropical Insect Science, 28, 30-36. https://doi.org/10.1017/S1742758408930435

[5] Dakouo, D., Nacro, S. and Sie, M. (1987) Seasonal Evolution of the Rice Gall Midge Infestations, Orseolia oryzivora H. et G. (Diptera, Cecidomyiidae) in the South-West of Burkina Faso. Insect Science and Its Application, 9, 469-473. https://doi.org/10.1017/S1742758400010985

[6] Bonzi, S.M. (1979) Results of the First Investigations on Insect Pests of Rice in Haute-Volta. West Africa Rice Development Association on Integrated Pests and Diseases Management, Bobo-Dioulasso, 17-22 September 1979, 9 p.

[7] Nwilene, F.E., Nwanze, K.F. and Okhidievbie, O. (2006) African Rice Gall Midge: Biology, Ecology and Control-Field Guide and Technical Manual. Africa Rice Center (WARDA), Cotonou, $24 \mathrm{p}$.

[8] Guinko, S. (1984) Haute Volta Vegetation. PhD Dissertation, University of Bor- 
deaux III, Bordeaux, 145 p.

[9] Johnson, D.E. (1997) Weeds of Rice in West Africa, Bouaké, Côte d'Ivoire. 312 p.

[10] Nacro, S. and Nenon, J.P. (2009) Comparative Study of the Morphology of the Ovipositor of Platygaster diplosisae (Hymenoptera: Platygasteridae) and Aprostocetus procerae (Hymenoptera: Eulophidae) Two Parasitoids Associated with the African Rice Gall Midge, Orseolia oryzivora (Diptera: Cecidomyiidae). Psyche, 2009, Article ID: 675242. https://doi.org/10.1155/2009/675242

[11] Ba, N.M. (2003) Annual Cycle of the African Rice Gall Midge, Orseolia oryzivora Harris et Gagné (Diptera: Cecidomyiidae) in Relation with Its Host Plants, Its Parasitoids and Some Cultural Practices in South-West of Burkina Faso. PhD Thesis in Biological and Applied Sciences, Option: Animal Biology and Ecology. Training and Research Unit on Life and Earth Science (UFR/SVT). University of Ouagadougou, Ouagadougou, $121 \mathrm{p}$.

[12] Nacro, S. (1994) Analysis of a Tritrophic System: The Rice Gall Midge and Its Parasitoids in Burkina Faso. PhD Thesis of University of Rennes I, France. Mention: Biological Sciences. U.F.R. Life and Environment Sciences, University of Rennes I, France. 179 p.

[13] Nacro, S., Dakouo, D. and Heinrichs, E.A. (1995) Population Dynamics, Host Plant Damage and Parasitism Associated with the African Rice Gall Midge in Southern Burkina Faso. Insect Science and Its Application, 16, 251-257. https://doi.org/10.1017/S1742758400017252

[14] Bonzi, S.M. (1980) Some Wild Host Plants of the Rice Gall Midge, Orseolia oryzae W.M. (Diptera: Cecidomyiidae) in Haute Volta. West Africa Rice Development Association Techn. Newsl., 2, 5-6.

[15] Sama, K., Nacro, S., Thiaw, C. and Dakouo, D. (2016) Incidence of the African Rice Gall Midge (AfRGM), Orseolia oryzivora H. \& G. in Relation with Period of Rice Transplanting in the Kou Valley, Burkina Faso. Advances in Entomology, 4, 97-103. https://doi.org/10.4236/ae.2016.42011

[16] Ouattara, D., Nacro, S., Dabire, R., Bama, H. and Dakouo, D. (2018) Effect of Transplanting Zone and Dates on Pre-Imaginal Populations, Parasitism and Attacks of Major Insect Pests of Rice on the Rice-Growing Area of la Vallée du Kou (Bobo-Dioulasso). Environment and Ecology Research, 6, 284-396.

https://doi.org/10.13189/eer.2018.060408 